\title{
Research of Power Generator Prototype Development and Integration into Autonomous Robotic Systems
}

\author{
$1^{\text {st }}$ Matutis Vaidotas \\ Faculty of Electronics and \\ Informatics \\ Vilniaus Kolegija University of \\ Applied Sciences \\ Vilnius, Lithuania \\ v.matutis@eif.viko.lt \\ $4^{\text {th }}$ Cesnauskas Simonas \\ Faculty of Electronics and \\ Informatics \\ Vilniaus Kolegija University of \\ Applied Sciences \\ Vilnius, Lithuania \\ s.cesnauskas@eif.viko.lt
}

\author{
$2^{\text {nd }}$ Savulioniene Loreta \\ Faculty of Electronics and \\ Informatics \\ Vilniaus Kolegija University of \\ Applied Sciences \\ Vilnius, Lithuania \\ l.savulioniene@eif.viko.lt
}

\author{
$3^{\text {rd }}$ Sakalys Paulius \\ Faculty of Electronics and \\ Informatics \\ Vilniaus Kolegija University of \\ Applied Sciences \\ Vilnius, Lithuania \\ p.sakalys@eif.viko.lt
}

\begin{abstract}
The aim of the research is to perform experimental research based on patented technology to study the efficiency and applicability of it in the power supply circuits of autonomous robotic systems. Ensuring longer autonomous operation of the robotic system, was chosen electric car as the object of practical application at this stage of investigations to improve a process generation, utilization and regeneration of electricity. The article reviews the difficulties of technologies and aspects of their practical application. Described research methodology and a stand of investigations. Presented the results and conclusions of the performed simulation tests and practical measurements of the prototype electrodynamic parameters.
\end{abstract}

Keywords - robotic system, electricity generator, regeneration, electric car.

\section{INTRODUCTION}

Members of the team - both teachers and students are united by the idea to explore opportunities of creation of a generator for autonomic robotic systems. One of such systems accessible for research and not too complicated in the beginning can be an electric car. This system is partly autonomic in the aspect of its control; however, its electric circuit is fully autonomic.
The base of this research is a patented [8] idea (the Patent No. LT-6714B; the Application No. 2019-065). The patented invention was created upon striving to increase the distance covered by an electric car after a single charging its battery at a stationary charging station. The goal of the invention is use of a mobile electric power generator based on an environmentally friendly technology in combination with wind power (both kinetic and potential energy of air mass formed on movement of the car) that is equipped with a compensatory mechanism of a simple design (in principle, it is a component of an electric car involved in charging the battery during the car's movement). The mock-up of a wind turbine is presented in Fig.1 below.

Analyzing of analogous ideas shows that a majority of them do not achieve the efficiency required for practical application, because the losses exceed the expected level on a certain stage (phase) and the possible efficiency becomes negative (that means losses). So, the team agreed to analyze each phase and to carry out practical measurements on a test stand for searching the best efficiency for each of this phase; if possible, computer modelling media shall be applied or created for up-andcoming studies. 


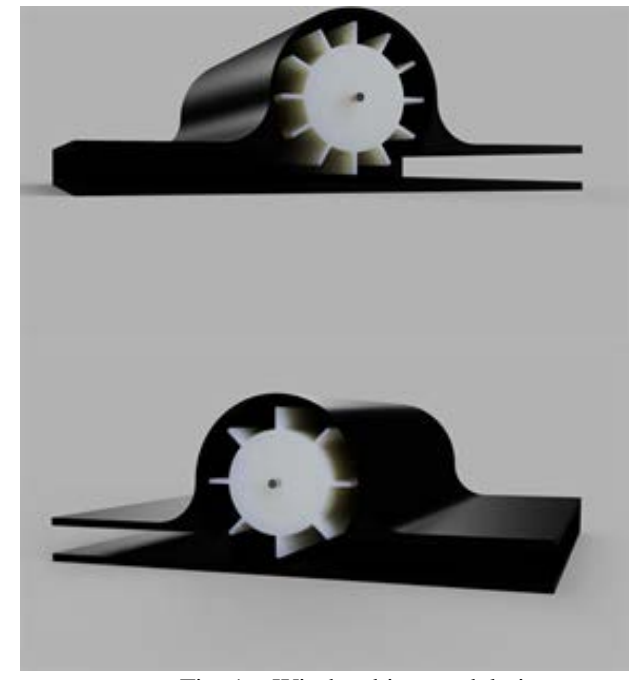

Fig. 1. Wind turbine model view.

To achieve the efficiency of a generator for electric cars that can provide a practical benefit, an integrated approach (Matutis, 2008) [7] is required, because it involves mechanics, electromechanics, electronics and some other areas of practical physics. On movement of an electric car, transformation of air flow around it into electric power required for charging the accumulator is one of the possible versions. Use of air flow power is analyzed in studies related to practical application of wind power systems where it is tried to use kinetic energy of air flow to the maximum possible extent. It was decided to carry out a practical analysis of this aspect in the first phase. The key problem of the said phase was a need to establish the number of wings of a chosen wind turbine that would ensure the best efficiency. The chosen geometric design of the turbine (Fig.1) is the simplest and is sensitive to environmental impact to the minimum extent. The design of the wings is simple as well; however, it ensures positive efficiency (in mechanical aspect) because of the relevant ratio of force levers.

However, the most interesting and uncertain factor remains use of air flow efficiency depending on the number of turbine wings. Such a formulation of the run of the study enabled starting to create a laboratory stand upon applying the available means and involving students in the works. It was planned to print a majority of details for the mock-up by $3 \mathrm{D}$ printers - these works were useful for developing skills of the students in design and manufacture, improved their figurative thinking and their abilities to convey it. In addition, they included modelling, programming and practical manufacturing educative activities. The short involvement of students in the project was highly beneficial both for them and for the total process of education at the College.

While talking about the consequences of a long-term involvement in such a project and the benefit provided, it should be remembered that the essence of the study was integrated approach, i.e. complexity. In this multi-phase study, almost each phase was related to a new area, such as mechanics, electromechanics, electronics and so on. In addition, each of the said areas was bound with other ones, so maintenance of the positive efficiency on transfer from one phase to another required to understand the interaction of the said areas and their integrity and to take them into consideration. In the process of education, this predetermines the general mastering of the conception of the surrounding world's integrity that is very important for our young generation to survive in the period tormented by crises and to create the future for themselves and their children...

Talking about the methodology of the study, the most effective and simple (in the aspect related to the design of the stand) way to find an answer to the put question would probably be measuring the behavior of the turbine at constant air flow and variable number of turbine wings. For the said purpose, a large number of rotors of different configurations (with different numbers of wings) (Fig.1) shall be made using the available 3D printers. Upon taking into account later aspects of practical application, it would be purposeful to measure two parameters - the starting point when the turbine starts its movement (rotation) and the torque developed by the rotating turbine in its internal cavity. Measurements of the torque can be carried out on gradual increasing the load and observing the turbine rotational speed. Such a curve was drawn at the constant air flow (that remains the same on any changes of the turbine rotor's configuration or in absence of them) and describes a turbine with a certain number of wings. If we suppose that varying the number of wings causes changes of the turbine characteristics, these measurements will enable entering the relevant data to the programmed computer simulator and providing more detailed clarification of the results of practical measurements through their abstraction.

The opportunity of involvement in discussions on the run of the said study, designing of the stand, carrying out the measurements, presentation \& analysis of the results, their transfer to the simulation medium, summarizing the results and presenting the conclusions provides to students of our Faculty a totality of practical skills required in the future professional activities of electronic engineers

\section{THE REVIEW OF THE THEORETICAL FRAMEWORK}

While speaking about wind power engineering, the wind power potential is usually analyzed; however, not the total power of moving air flow is technologically transferred into the power useful for the consumer.

In this analysis, wind is described as horizontal movement of air mass that is caused by the temperature difference on the surface of the Earth, because the Sun does not warm the surface of the Earth and the air of the atmosphere to the same extent. Cold air is heavier - in the atmosphere, it moves downward, thus forming high pressure zones. Warm air is easier, and it moves upwards in the atmosphere, thus forming low pressure zones. Air 
moves from a high-pressure zone to a low-pressure zone until the pressures become the same. Although wind is identified a renewable source of energy, it (because of its origin) is a phenomenon formed by the solar radiation. On analyzing the vertical section of the atmosphere, winds are divided to geostrophic winds and surface winds (Kytra, 2006) [6]. A geostrophic wind is formed on the height over $1 \mathrm{~km}$; a wind formed on a lower height is a surface wind. In a layer of a surface wind, a zone of wind with the height up to $100 \mathrm{~m}$ may be found, because movement of air masses in the said zone is strongly affected by the roughness of the surface, i.e. inequalities of the surface of the Earth, buildings, plantations et cetera. It is natural that obstacles reduce the speed of the wind, so a higher speed of wind is observed in open territories, over oceans and seas. Close to obstacles, the windward and downwind zones are observed; they express themselves by the wind turbulence and its speed decrease.

The speed $\mathrm{v}$ is the key characteristic usable in wind power engineering analysis. According to the theory of classical mechanics, kinetic energy E of air flow (air mass) movement (Augulis, Jotautis \& Rutkuniene, 2012) [1], shall be expressed as follows:

$$
E=\frac{1}{2} m v^{2}
$$

here: $\mathrm{v}$ - the wind speed, $\mathrm{m} / \mathrm{s}$;

$$
\mathrm{m} \text { - the air mass, } \mathrm{kg} \text {. }
$$

The air mass moving through the wind wheel can be expressed as follows (Boyle, 2012) [5]:

$$
m=\rho V=\rho A l=\rho A v(2)
$$

here: $\quad \rho$ - air density, $\mathrm{kg} / \mathrm{m}^{3}$;

$\mathrm{V}$ - air volume, $\mathrm{m}^{3}$;

A - area, $\mathrm{m}^{2}$;

$\mathrm{l}$ - length, $\mathrm{m}$;

$\mathrm{v}-$ wind speed, $\mathrm{m} / \mathrm{s}$;

$\mathrm{t}$ - time, $\mathrm{s}$.

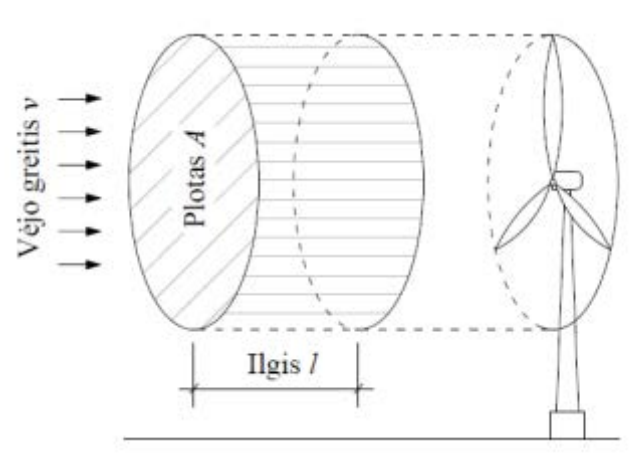

Fig. 2. The scheme of the air mass moving through the wind wheel (Boyle, 2012).
So, the formula (1) may be expressed as follows (Mukund, 2006) [9]

$$
E=\frac{1}{2} m v^{2}=\frac{1}{2}(\rho A v t) v^{2}=\frac{1}{2} \rho A t v^{3} .
$$

Power P of air mass or air flow shall be expressed as power change per time unit (Mukund, 2006) [9]:

$$
P=\frac{E}{t}=\frac{\frac{1}{2} \rho A t v^{3}}{t}=\frac{1}{2} \rho A v^{3} .
$$

We can see from the formula (3) that the maximum theoretical power of wind stream directly depends on the third degree of the value of the wind speed, so the wind speed is a key parameter usable for establishing technoeconomical characteristics of wind.

The primary technological equipment that contacts with the air flow is the wind wheel. The power Pm_in, i. e. the power obtained from the air flow per time unit, can be calculated according to the formula (1) upon taking into account that power obtained by the wind wheel from the air flow depends on the difference between the wind speed before the wind wheel $(\mathrm{v})$ and the wind speed behind the wind wheel (v0 ) (Mukund, 2006) [9]:

$P_{n \_ \text {in }}=\frac{1}{2} \frac{m}{t}\left(v^{2}-v_{0}^{2}\right)=\frac{1}{2} G\left(v^{2}-v_{0}^{2}\right) ;$

the wind speed before the wind wheel, $\mathrm{m} / \mathrm{s}$; $\mathrm{v} 0$ - the wind speed behind the wind wheel, $\mathrm{m} / \mathrm{s}$; $\mathrm{G}-$ the mass air flow, $\mathrm{kg} / \mathrm{s}$.

According to the formula (2), the mass air flow $G$ may be expressed as an arithmetical average of the wind speed before the wind wheel and the wind speed behind the wind wheel (Mukund, 2006) [9]:

$$
G=\rho A \frac{v+v_{0}}{2}
$$

then:

$$
P_{\alpha-\alpha}=\frac{1}{2}\left(\rho A \frac{v+v_{0}}{2}\right) \cdot\left(v^{2}-v_{0}^{2}\right)=\frac{1}{2} \rho A v^{3} \frac{\left(1+\frac{v_{0}}{v}\right) \cdot\left(1-\left(\frac{v_{0}}{v}\right)^{2}\right)}{2} .
$$

The last member in the formula (7) singles out the ratio between the wind speed before the wind wheel and the wind speed behind the wind wheel, thus describing the property of the wind wheel to adopt useful kinetic wind energy, and this non-dimensional value is referred to as the 
efficiency of the wind wheel, or the wind wheel's power factor cp:

$$
c_{p}=\frac{\left(1+\frac{v_{0}}{v}\right) \cdot\left(1-\left(\frac{v_{0}}{v}\right)^{2}\right)}{2} ;
$$

$$
P_{\mathrm{m}_{-} \text {in }}=\frac{1}{2} \rho A v^{3} c_{p}
$$

The maximum power factor cp of an ideal wind wheel equals to 0.593 and takes place when the wind speed behind the wind wheel is suspended upon the ratio $2 / 3$, as compared to the wind speed before the wind wheel. This law was formulated and proved by German scientist Albert Betz in 1919. A.Betz published the results of his study in 1920 in the paper „Das Maximum der theoretisch möglichen Ausnützung des Windes durch Windmotoren“ (,The theoretical limit of power of a wind turbine using the wind energy to the maximum extent”) (Betz, 1920) [4], and since the said time, A. Betz's law has not been replaced or altered or proved otherwise A. Betz's law describes the maximum power transformation of a certain operating point; however, on operation of a wind turbine, other losses appear as well too.

Designs of wind wheels can be various; their technical propertied and the ones related to wind power transformation differ as well.

\section{THE METHODOLOGY OF THE RESEARCH}

As it was mentioned above, designs of wind wheels vary, and our team had chosen one of them - the version of a turbine (Fig. 1). As a stand for tests, we can use an elementary analogue of a wind tunnel. The wind flow is generated by a fan; on its way, a prototype of a turbine is placed; in addition, one air flow meter is placed before the turbine and the second air flow meter - at the air flow output. As it was mentioned earlier, we measure two parameters: the starting point when the turbine starts moving (rotating) and the torque developed by the rotating turbine in its internal cavity. Torque measurements can be carried out on a gradual increasing the load and observing the rotational speed of the turbine. Such a curve drawn for a constant air flow (that remains the same after a change of the turbine rotor configuration) would describe a turbine with a certain number of wings. For this purpose, we print rotors of different configurations (with different numbers of wings) and then carry out the measurements at a constant air flow upon varying the number of turbine wings.

The practical measurements seem to be simple; however, the restrictions applicable both to the process of studies and the practical training prevented us at present from presentation of the collected data and their analysis. So, it was decided to present not only the computer simulation of the wind tunnel, but also some observations and measurements from the primary assembled model.

The simulations used Autodesk ${ }^{\circledR}$ CFD 7 [Autodesk CFD, 2021] [3] software to turn a 3D CAD workstation into a fully interactive liquid and gas test bench, thermal test rig, or wind tunnel. 3D layouts become interactive, at no cost to prototypes, revealing critical engineering information that is difficult to obtain through physical testing. Change the design of the model and we will see the same change in Autodesk ${ }^{\circledR}$ CFD right away. This software has been used in combination with Autodesk Fusion 3606 [Autodesk Fusion, 2021] [2], which is 3D and 2D modeling software with a fairly user-friendly environment that allows you to use it comfortably without much challenge. It is a powerful program that allows you to create complex and large-scale layouts. Thanks to Fusion 360's ability to import layouts of required materials directly from the manufacturer's catalogs, it is possible to save time by designing less significant components (bolts, nuts, profiles, etc.) and use that time to implement the basic layout. Also, the ability to simulate moving parts of the device (albeit limited) allows for a better understanding of the performance, durability of the final layout, and the anticipation and improvement of potential engineering mismatches.

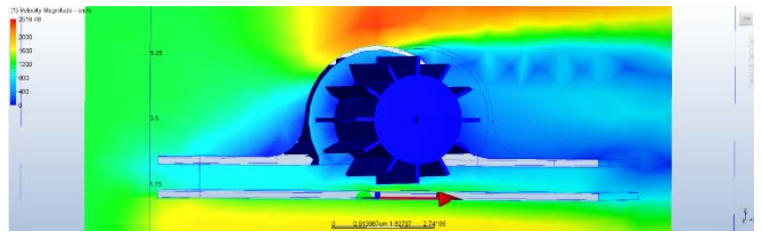

Fig. 3. The turbine in the wind tunnel simulation.

The initial situation of the wind tunnel is presented in Fig. 3 above. The chosen design of the wind turbine appeared to be not very effective. As one can see from the image of the simulation, a very weak air flow moves through the turbine wings and our goal is to achieve the maximum possible efficiency. The colored scale in the left part of the Figure indicates the intensity of the air flow in colors. The colored distribution presented in the Figure shows where air flows are most intensive. So, it can be presumed that an improvement of the design of the turbine body upon preserving the existing chosen geometry of the turbine is required.

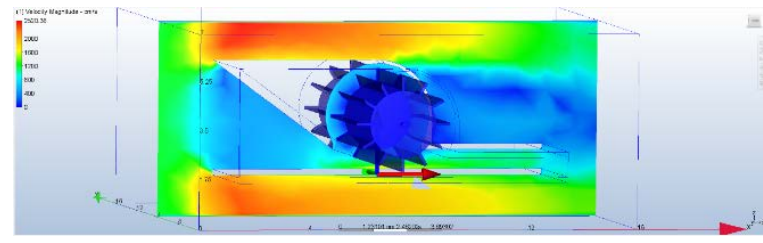

Fig. 4. The corrected turbine in the wind tunnel simulation.

It was decided to broaden the air inlet and to repeat a simulation once more. The repeated simulation is presented in Fig. 4 above; it can be seen, that now, the 
intensity of the air flow through the wings grows considerably.

Based on the highlights observed in these simulations, a study model was printed on 3D printers, the incision of which is shown in Fig. 5

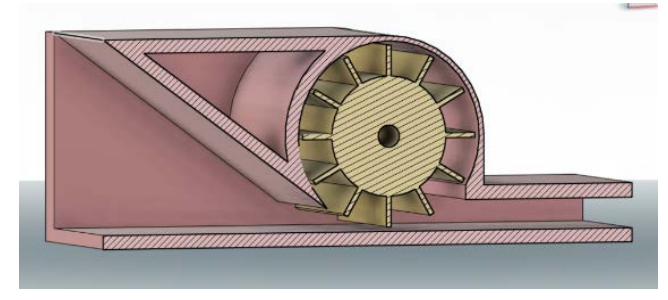

Fig. 5. The incision of model.

With 3D printers, all the necessary parts of the model were printed. In Fig. 6 we see a pictures of the work process.

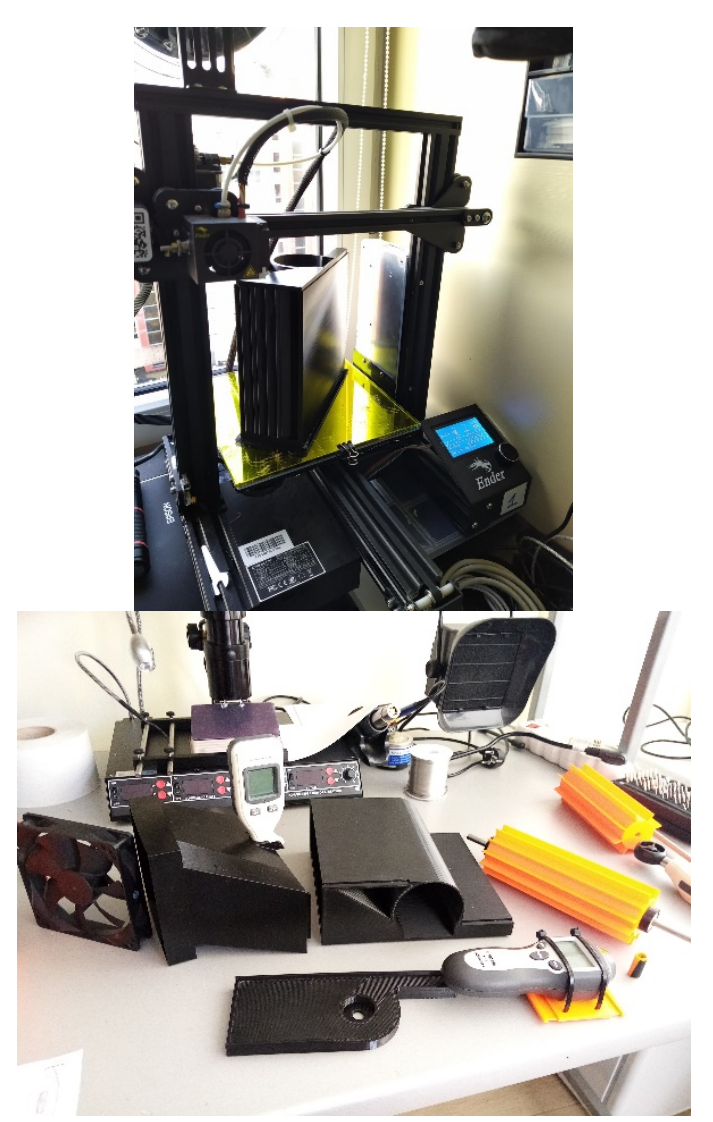

Fig. 6. Model printing process.

We see the finally assembled model in Fig. 7

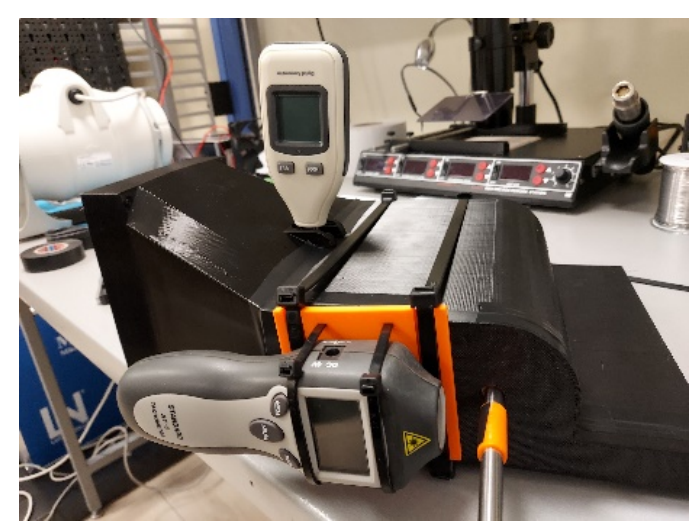

Fig. 7. The model was collected and prepared for research.

We plan step by step to identify coherently the maximum efficiency on each phase of the study and - after integrated coordination and summation of all phases - we hope to obtain a practically applicable electric generator for electric cars that enables to increase the distance coverable by a car after a single charging its battery at a stationary charging station. As it was mentioned earlier, an electric car may be considered a certain autonomic robotic system, so in a broader sense it is the first step towards creation of a generator for autonomic robotic systems.

In such a way, the methodology of the study, applicable methods and the strategy of the run of the experimental research chosen by our team can be defined. The scope of the experiments will be expanded in the future.

\section{THE RESULTS OF THE STUDY AND THE CONCLUSIONS}

The result of this first phase of the study is an obvious improvement of the turbine body upon applying the results of computer simulation.

As for the first results of the practical tests, in the beginning the workshop failed to move the impellers with the planned fans and the air flow generated by them. When the impeller was still able to move, the required air flow was about $100 \mathrm{~km} / \mathrm{h}$ (we used a compressor), the impeller rotation speed was recorded at about $1100 \mathrm{rpm}$; however, very high damping because after stopping the air flow in one revolution, the speed dropped to $200 \mathrm{rpm}$ and stopped completely. Meanwhile, the speed of the outgoing air flow when the impeller was rotating was only $20 \mathrm{~km} / \mathrm{h}$. Initially planned fans for airflow generation were significantly weaker. The computer fan (originally intended) generated an air flow of only about $7 \mathrm{~km} / \mathrm{h}$, while the exhaust fan that was still available generated an air flow of up to $20 \mathrm{~km}$ / h. However, this was not enough for the first attempts.

A new generation of polymer bearings was used in the model, which should ensure a sufficiently low resistance. However, as experiments have shown, the resistance is quite high. Such a damping factor even surprised. Of course, this could also be influenced by the 
geometrical inaccuracies and unforeseen deformations of the printed plastic parts of the layout. Here we will have to work on centering the model impeller and compensating for unexpected deformations.

The scope of the experiments will be expanded. Preliminary measurement results and observations have been performed, create preconditions for further improvement of the model and preparation for the planned measurements. We regret the incomplete scope of the experiments and apologize to colleagues for this, but this was due to circumstances beyond our control.

Initial tests have been carried out, and this is a great achievement, despite the fact that the results for this minute have not lived up to expectations - and most importantly, we now have a clear starting point. Also, the geometry of the air flow inlet was chosen in the model at the initial stage only half the height of the wing, which also limited the flexibility of the research. The team proposes to further improve the model - to make an adjustable supply air flow valve so that we can dynamically change the area of attack on the turbine blades. Such an improvement will allow the construction of a more promising model, which will allow more flexibility in planning further research and measurements.

These are very important technical achievements.

In summary, must be underlined:

- The very important social role of this phase in the training process is that the youth starts taking an interest in research activities and practical application of technological solutions important for the total community that guide towards environmental conservation and protection as well as care about each other. It will help our new generation, in addition to developing the sense of social responsibility and understanding, to observe and adopt the inevitability of integrity. In the higher education process, integration of such studies is undoubtedly a very useful and promising tool.
- $\quad$ Technically, several more steps have been taken to achieve the best possible efficiency, which encourages the team to be even more focused and concentrated on the improvement and development of the model. It is also a very important piece of work for the environment around us, as the desired result is an environmentally friendly device, ecologically clean and using renewable energy resources.

\section{REFERENCES}

[1] Augulis, L., Jotautis, A., \& Ruktuniene, D. (2012). Fizika mechanika, termodinamika, elektromagnetizmas: mokomoji knyga. Kaunas: Technologija. DOI: https://www.ebooks.ktu.lt/eb/656/fizika_mechanika_termodinami ka_elektromagnetizmas/.

[2] Autodesk (2021). Autodesk fusion abilities. Retrieved from https://academy.autodesk.com/getting-started-fusion360\#: :text=Fusion\%20360\%20helps\%20students\%20and,turn\%2 0your\%20ideas\%20into\%20reality

[3] Autodesk (2021). What is Autodesk CFD. Retrieved from https://www.autodesk.com/products/cfd/overview\#: :text=Autode sk\%20CFD\%20is\%20a\%20computational,into\%20fluid\%20flow \%20design\%20performance.

[4] Betz, A. (1920) Das Maximum der theoretisch möglichen Ausnützung des Windes durch Windmotoren. Zeitschrift für das gesamte Turbinenwesen, 26, 307-309. (In German)

[5] Boyle, G. (2012). Renewable energy: power for a sustainable future. Oxford: Oxford University Press.

[6] Kytra, S. (2006). Atsinaujinantys energijos saltiniai: vadovèlis aukstosioms mokykloms. Kaunas: Technologija

[7] Matutis, V. (2008). Political idea and national security. Vadybos šiuolaikiness tendencijos $=$ Modern tendencies of management : mokslo darbu rinkinys, 219. ISSN: 978-9955-423-69-0. DOI: www.lka.lt/download/1393/vadyba makstutis.pdf

[8] Matutis, V. \& Matutis, M. (2020). Generator for electric cars. Vilnius: Official Bulletin of the State Patent Bureau of the Republic of Lithuania, 28. ISSN: 2029-2309,

Patent No: LT-6714. https://vpb.lrv.lt/uploads/vpb/documents/files/VPB-OB-Nr062020-03-25-1d.pdf

[9] Mukund, R.P. (2006). Wind and solar power systems: design, analysis, and operation. Boca Raton: Taylor \& Francis. 